\title{
A study of RFID adoption for vehicle tracking in a container terminal
}

\author{
S. L. Ting, L. X. Wang, W. H. Ip \\ The Hong Kong Polytechnic University (HONG KONG) \\ eb_jackyting@,hotmail.com;jacky.ting@polyu.edu.bk; cejacky@inet.polye.edu.bk
}

Received October 2011

Accepted March 2012

\section{Abstract:}

Purpose: Numerous studies suggest that Radio Frequency Identification (RFID) technology can provide improved container handling efficiency; however, there is a relative lack of research concerning tracking and monitoring of vehicle movement in the container terminal environment. This study therefore aims at assessing the feasibility of applying RFID for vehicle tracking purposes in a container terminal.

Design/methodology/approach: This study makes use of a series of experiments in a container terminal in order to discuss the factors that affect the use of RFID in the terminal. The possibility and accuracy of using RFID in such a challenging environment is also investigated. These propositions are investigated by a means of case study.

Findings: The experimental results indicate that RFID communication is good in the container areas which are nearly all the terminal area. However, in other areas such as the sea side and free area, the performance is not so good and 100\% readability can only be achieved in $5 \mathrm{~m}$ and $10 \mathrm{~m}$.

Originality/value: The container terminal environment, with different transport vehicles for onward transportation, will affect the performance of RFID readability. Poor setup of the RFID reader and tag will lower the feasibility of RFID adoption as well as increase the cost. In order to address the challenges of 
implementing RFID in such an environment, this paper describes a series of real site testing experiments to study the RFID performance. This represents an original contribution to research and practice in RFID adoption in container terminals.

Keywords: case study, container terminal, radio frequency identification (RFID), vehicle tracking system

\section{Introduction}

With the advance of globalization, transportation is playing an important role. Numerous containers are transported from port to port, from vehicle to vehicle, every day. As transportation distances become longer and the volume of international transportation increases, many companies are involved in the transportation of one assignment from one location to another. It is hard to manage the containers, such as how to arrange the container schedule and route for avoiding heavy traffic; how to track the container locations continuously. Additionally, containers look the same and it is also hard to identify them in the terminal. These challenges make tracking of the vehicles and containers very important. Efficient information can help the users to manage their transportations. This is the reason why there are numerous studies using information and communication technologies in vehicle and container tracking.

To deal with this problem, recently developed technology provides an efficient way. Radio Frequency Identification (RFID) is an emerging technology that uses wireless radio to identify objects from a distance without requiring line of sight or physical contact (Borriello, 2005). RFID enables the user to capture real-time information in fast moving and bulky product flows with the aim of achieving a high degree of efficiency and assuring high quality. The components of a typical RFID system include an RFID tag, an RFID reader, an RFID antenna, an RFID middleware and the backend system. The RFID tag is the identification device attached to the item to be tracked. The RFID reader and antenna are devices that can recognize the presence of RFID tags and read the information stored on them. The aim of RFID middleware is to process the transmission of information between the reader and other applications after receiving the information. Middleware is software that facilitates communication between the system and the RFID devices. Figure 1 shows a typical RFID system and illustrates how the elements fit together. 


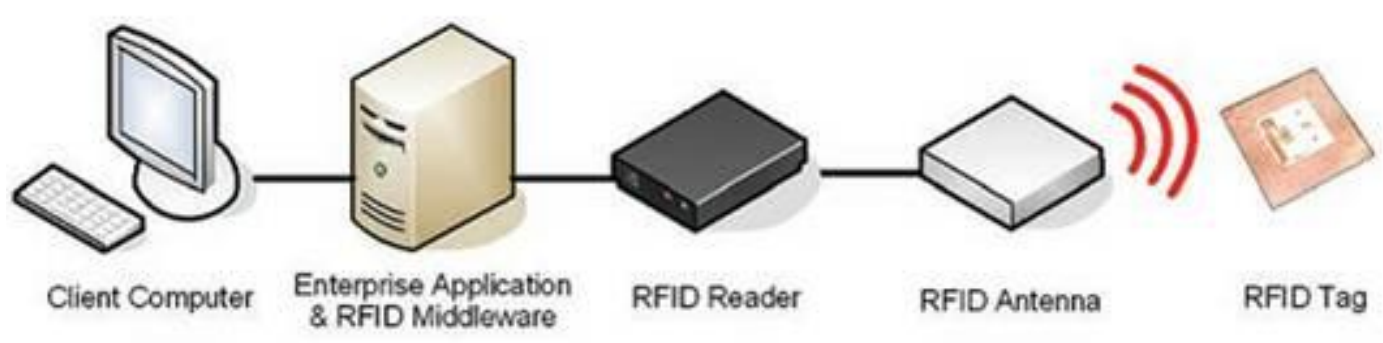

Figure 1. Basic Components of an RFID System (Kwok, Tsang \& Cheung, 2008)

Recently, the lower costs and the increasing capabilities of the RFID technique attract attention in keeping track and monitoring the containers in the terminal (Hsu, Shih \& Wang, 2009; Park, Dragovic \& Kim, 2009; Ngai et al., 2010). Woo, Choi, Kwak and Kim (2009) proposed an activity product state tracking system architecture which is able to track products even when they are in a box or a container. Abad et al. (2009) developed an RFID-based system for traceability and cold chain monitoring of food. Wang et al. (2009) proposed a RFID-based decision support system to monitor, trace and track products in containers. Chao and Lin (2009) analyzed critical factors affecting the adoption of a container security service, which is composed of auto-detection and RFID technologies, from the shippers' perspective. Cao and Xiao (2011) analyzed a propagation prediction model and the performance of a container RFID system under metallic container production circumstances. These applications encourage study of RFID to realize vehicle tracking in container terminals. However, although numerous studies involving the installation of RFID have demonstrated the benefits of better container handling efficiency, a relative lack of research concerning tracking and monitoring vehicle movement in the container terminal environment is appearance.

Vehicle tracking is a way to improve company efficiency and in effect, increase profitability, especially in the business of large vehicle fleets (Hsieh, Yu, Chen \& Hu, 2006). The tracking system is the enabling technology, and is the key to release the value trapped in asset management. By its non-contact, scan-based data reading characteristics, it automates the asset tracking and data acquisition that enables an enterprise to locate vehicles (i.e. cars, trucks, etc.) and even uses location information to optimize services. With the help of tracking information, the manager is able to access one or more driver locations and gets their status information on a real-time basis (i.e. checking if the drivers execute the order; if they follow the driving routes; if there is any traffic congestion, etc.). However, implementing RFID as a vehicle tracking system is difficult as the container terminal environment, which involves different transport vehicles for onward transportation, 
will affect the performance of RFID readability. Poor setup of the RFID reader and tag will lower the feasibility of RFID adoption, as well as increase the cost. In order to address the challenges of implementing RFID in a container terminal, this study examines the RFID performance in such an environment. Several real site testing experiments were conducted in a port and the results show that RFID is reliable and is capable of adoption in a container terminal environment.

\section{Current vehicle tracking technologies}

The tracking of vehicles and containers has become a very popular research topic in recent years and there are several techniques which have been applied.

To start with the simplest one - the "vehicle-card" technique (Rus, Bilcu, Egiazarian \& Rusu, 2004), makes use of STD phone booths and a specially designed vehiclecard. Vehicle owners are provided with a card that a driver carries to the nearest tracking point, basically a designated STD booth on a vehicle route or highway, at major stops and petrol stations. Details of the vehicle, coded on the card together with a simple numbered message, are transferred to a local telephone number using a Voice Response System. At the receiving end, the receiver uploads all incoming messages by email to a central hub, where it is processed and placed on a website. Vehicle owners or centralized controllers can keep track of where each of their vehicles are. Clearly a large scale human intervention makes this scheme unfit for a fully automated real-time system but it can be of interest for some very small level implementations.

There is another technique based on cellular infrastructure. Network Overlay Systems use cell phone infrastructure for locating vehicles (Kane, Vermaa \& Jaina, 2008). The cell centers with additional hardware and software assess the time of arrival (TOA) and angle of arrival (AOA) of radio signals from vehicles to compute the position of the vehicles. This information is sent to the tracking center through the cell link or a conventional link. Another technique used for locating vehicles computes the time difference for signals from two cell centers to reach the vehicle. This computation is made in a public platform and the position information is sent to the tracking center through the cell phone link. Unfortunately this approach cannot get the vehicle locations fairly accurately.

When the Navigation Satellite Timing and Ranging Global Position System (GPS) technique emerged, tracking of vehicles and containers became easier. GPS provides specially coded satellite signals that can be processed in a GPS receiver, enabling the receiver to compute position, velocity and time. Four GPS satellite 
signals are used to compute positions in three dimensions and the time offset in the receiver clock. The Space Segment of the system consists of the GPS satellites. These space vehicles send radio signals from space. The Control Segment consists of a system of tracking stations located around the world. These monitoring stations measure signals from the space vehicles that are incorporated into orbital models for each satellite. The models compute precise orbital data (ephemeris) and the space vehicle clock corrections for each satellite. The Master Control station uploads ephemeris and clock data to the space vehicles. The space vehicles then send subsets of the orbital ephemeris data to GPS receivers over radio signals. The GPS User Segment consists of the GPS receivers and the user community. GPS receivers convert space vehicle signals into position, velocity, and time estimates. Four satellites are required to compute the four dimensions of $X, Y, Z$ (position) and Time. GPS receivers are used for navigation, positioning, time dissemination, and other research (Lee, Oh \& Ryu, 2003). Haugen, Ayers, Anderson and Nissen (2002) used GPS to evaluate vehicle movement patterns and impacts during training maneuvers. Ayers, Wu, and Anderson (2004) evaluated the use of the GPS35-HVS GPS for vehicle tracking and found that GPS was able to monitor a vehicle position and dynamic properties. However there are still some limitations with GPS. On average, a satellite navigation receiver is accurate to within $15 \mathrm{~m}$. A number of positioning errors can occur, limiting accuracy to within 15-25 $\mathrm{m}$. The positioning errors are supposed to intensify when a fast moving vehicle is to be tracked and immediate longitude and latitude calculations are to be carried out (Kane et al., 2008). Additionally, GPS focuses on location tracking not objective tracking. The use barcodes is also a common technology for vehicle tracking.

For easy identifying and tracing of products and containers, barcode technology had been used in products and containers management for several years. Nowadays, RFID is beginning to replace barcode techniques because of the limitations of the old technology, especially in logistics. Compared with barcodes, RFID enables the capturing of real-time information in fast moving and bulky product flows with the aim of achieving a high degree of efficiency and assuring high quality. However, the barcode technique cannot benefit from ePedigree, which is an integral and sole data source containing a series of recorded digital product authentications proposed by EPCglobal (Kwok, Ting, Tsang, Lee \& Cheung, 2010), as well since containers cannot be opened to scan barcodes to check the products during transportation. RFID can however benefit from it, as it permits the collection of information and influences quality in real-time. Because of ePedigree, RFID technology also allows the tracking of items in real-time across the supply chain. When a product is transported for sale from a manufacturer to a wholesaler, the manufacturer 
initiates the pedigree. Another transaction takes place when the product passes from one wholesaler to another. This is recorded on receipt of the pedigree without any need for signing the pedigree. The pedigree is subsequently signed on the next outbound transaction to the retailer. Users can know which venues the products have passed through by reading the ePedigree.

With the widespread use of RFID tags, many researchers have applied this new technique to the monitoring of the container transportation. Park, Oh, Cheong and Lee (2006) proposed a Container Yard Management System (CYMS). The main purpose of their system is to ensure the security of containers, to prevent the loss of goods in containers and to track and trace containers. The structure of this system is shown below in Figure 2.

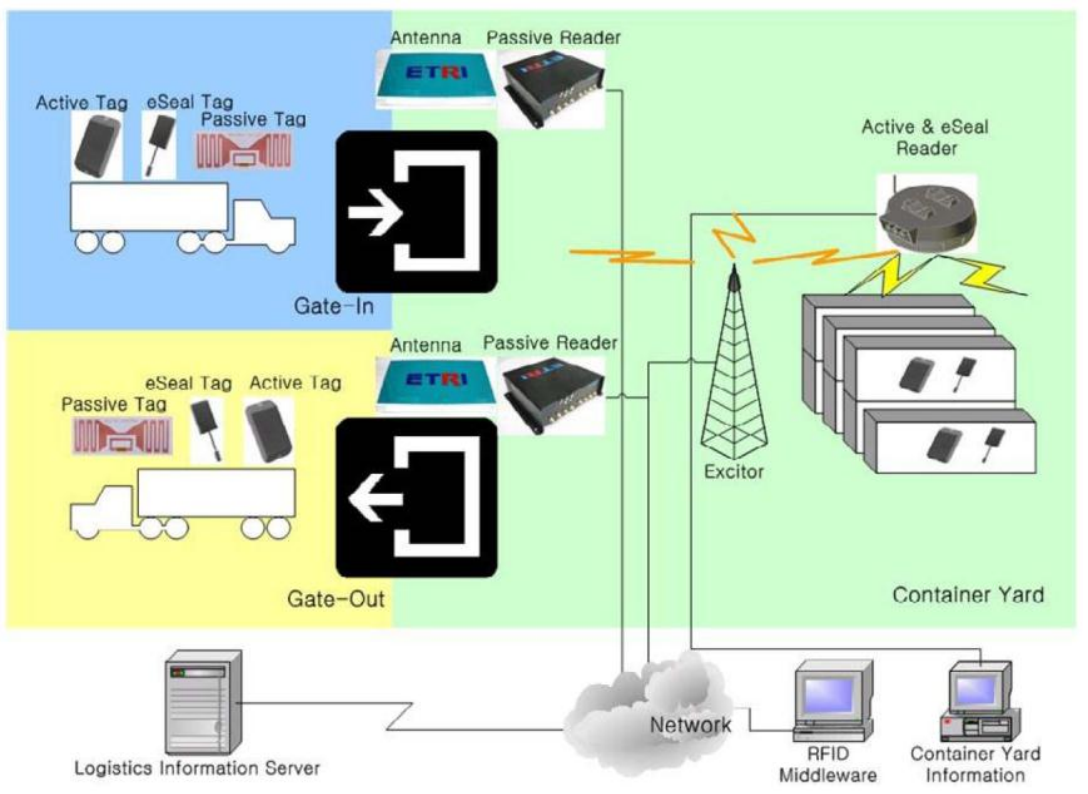

Figure 2. The structure of CYMS with RFID technologies (Park et al., 2006)

At the gate, the passive reader and the excitor are installed to read the tags on trucks and containers. In the yard, electronic seal tags are used to check the container security. One reader is an active and electronic seal reader and the other reader is an excitor, which transmits a signal as to the status of the tags. The excitor can make tags fall asleep or wake them up. Active tags and electronic sealed tags use a battery in operation. When a tag is used for a prolonged period in the field, the battery tag is set to sleep status as the tags do not need to communicate with the reader (Finkenzeller, 2003). The reader begins to communicate with the tags when the excitor changes the tag's status from sleep to wake-up by sending a "ModeChange" message to the backend system. 
Furthermore, Jedermann, Behrens, Westphal and Lang (2006) developed a realtime autonomous sensor system to monitor products when they are transported. The backend system can access the on-the-road sensors of this system. The system also separates the sensors and the RFID tags, so the system can be easily expanded to handle special sensor requirements. The use of RFID also can realize task achievement data and information about the products automatically when the products are loaded or unloaded.

In all the technologies stated above, it is found RFID has a good performance in vehicle tracking especially for the management of containers. However, the environment of container terminal is very different from a normal environment. Though there are lots of studies on vehicle tracking and container management, research on the feasibility of RFID technology applied in the terminal environmental is lacking. Consequently, in this study, several experiments are designed to test the performance of RFID in the terminal for container management and tracking. A case study is also conducted to show and to discuss the experimental results. The details are introduced in the following sections.

\section{Research methodology - design of experiments}

In setting up an RFID-enabled vehicle tracking system in the terminal, there are a numbers of factors affecting the radio wave communication that needed to be considered beforehand. On the basis of these factors, experiments can be devised and tested on these parameters.

\subsection{Parameters to be tested}

The following parameters for running RFID in a terminal are to be tested:

- Distance. Roads in the terminals are different; and different kinds of RF reader have different readable ranges. Although the range of reader will normally be stated, however, the condition in the terminal is quite different from any other situation. So, distance is one of the parameters that need to be considered.

- Penetration. In the terminal, there are many containers which are actually barriers to the RF communication. Since penetration and read range trades off each other, using a long range RF reader such as microwave or UHF will have less penetration ability. This is because the higher the frequency, the easier RFID is affected by the environment. For the application of using 
RFID to track a loader, penetration is a very important parameter because the radio wave may need to pass through a lot of containers after reaching the tag, or the lack of penetration will need more tracking points.

- $\quad$ Speed. Another variable is the speed. If one part of the system, i.e., tag or reader is running at a high speed, there is a chance that no communication will occur. So, it is important to test if the communication is successful when the equipment is running at the highest speed.

- Distance between two tags. Each reader has its own read range. For the application of tracking a vehicle, one tag is representing one area, and the read range of the reader should not cover more than 1 tag which may lead to confusion. So, the separation of 2 tags has to be considered carefully. This variable can also be determined by the distance of the communications.

\subsection{Description of experiment}

This experiment aims to find out whether the RFID technology is useful in the terminal environment so that it can be used as a vehicle tracking system in the terminal. The environment of a container terminal is very different from the normal environment or indoors. The following are some special conditions in a terminal:

- It is a outdoor environment that is affected by change of weather

- There are many metal containers that will affect RF wave communication

- Vehicle routes are not well defined

- Equipment is difficult to install in the terminal

Based on the above operational features and the parameters identified to determine success in RFID communication, distance, penetration, speed, experiments are designed to test the equipment capabilities in meeting project requirements.

The experiments planned can be categorized into 2 sets:

- The first stage experiments are to test how the effectiveness of the RFID communication system is affected by parameters such as distance, speed and penetration 
- In the second stage experiments, trial tests will be run to test the effectiveness of the system in different conditions to simulate the real operation situations

All tests need the presence of a patrol car. The following equipment is installed in patrol car:

- Reader and control unit. These are placed and locked inside the vehicle. When the vehicle is going through in the yard, the reader will sense the tag and send data to the server

- Cross link. It acts as a link between the control unit and notebook. Since the reader only has a LAN connection, it is necessary to use a cross link to connect both the "computers"

- Notebook. The Notebook acts as a server, database and is linked to the reader. It is equipped with software which can check whether the tags are being detected and the location of vehicle

- Tags. Tags are placed in the yard, and all the tag numbers are recorded and used to associate with its location

- Electronic power converter. Since there is no other power source inside the vehicle, an electronic converter is used to supply power to the notebook, reader and the switch. The converter changes the DC power from the vehicle to $220 \mathrm{~V}$ AC power for the equipment. A control unit, which is linked to the power supply from the vehicle, is shown in Figure 3

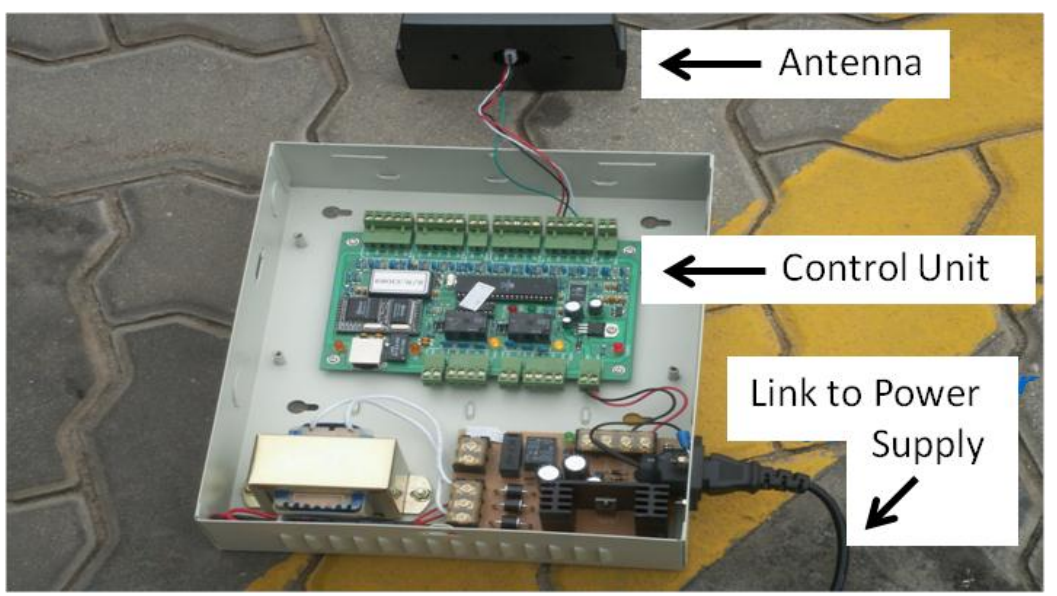

Figure 3. Architecture of RFID communications 


\section{Case study}

\subsection{Case study background}

A case study has been conducted in collaboration with YANICT (Anonymous name), a leading world port investor, developer and operator in the Pearl Delta Region in China, to carry out a feasibility study of using RFID in a container terminal. The company is responsible for operating and managing various phases in a port. It has one of the biggest container terminals in China with 208 hectares and 9 berths. Because of the keen competition, the terminal plans to use RFID to facilitate its operation and compete with other ports in the South China Coastal area. Table 1 summarizes the overall port the study area.

\begin{tabular}{|l|r|}
\hline Total Area (hectares) & 208 \\
\hline Container Berths & 9 \\
\hline Total Berth Length (m) & 3,750 \\
\hline Water Depth Alongside (m) & $14-16$ \\
\hline Water Depth of Waterways (m) & $14-16$ \\
\hline
\end{tabular}

Table 1. Facts of study area

\subsection{Challenges faced by YANICT}

\section{Vehicle Tracking Problems}

In the existing Operational Management System (OMS) of YANICT, only the location of Rubber-Tyre Gantry Cranes (RTGC) and the Front/Top Loader is recorded, there is no function for tracking the internal vehicles including internal tractors and patrol cars. However, the operators need to know the location of internal vehicles including patrol cars. The tracking system cannot act as the same way after the Front Loaders or Top Loaders. When the Front Loaders or Top Loaders go to a specific location to do their work, the loader driver would input the location to the system for confirmation. However, since internal tractors and patrol cars go around the yard, the yard is so large that the tower cannot track the location continuously in the way the Front Loader is used.

Secondly, the traffic situation in the yard is not visible to the operators. It is very important for the operators to know the traffic conditions in the yard. However, the area monitored by one patrol car (Area Supervisor) is so large that it is not possible to figure out all sorts of traffic problems in that area. If one of the roads in an area has heavy traffic, the patrol car can only notice it if it passes that road or somebody informs the tower. Although the Tower cannot solve the problem by using OMS, they could contact the Area Supervisor to go to the congested area and guide the 
driver in the area. However, it takes time to do so. On the other hand, the tracking of the traffic situation is even more important with the opening of Phase $3 \mathrm{~B}$ of the container terminal. This is because it will be more difficult to manage the traffic in such a large area. The suggested system is then necessary to show the traffic condition, in addition to the tracking system.

Thirdly, the jobs cannot be assigned to the patrol car efficiently. As stated above, the Area Supervisor acts only when he sees an incident happens or is notified. When some incident happens and the Tower is notified by the system or other persons, the Tower needs to find the nearest patrol car to direct to the incident area. So, in addition to tracking the vehicle, the system also needs to have the function of finding the nearest patrol car in order to act as fast as possible.

\section{Loader Tracking Problems}

In the current status, the tracking of loaders in YANICT is updated manually. In the existing OMS, there is a function that tracks on the location of the Front Loader and Top Loader. However, the method of locating the Loader is that every time a driver goes to a specific place to work, he/she will update the location to the system manually. It increases the work load of the driver.

Furthermore, the tracking of the loader is not a continuous process. The OMS shows the location of the Loader graphically. However, the existing system cannot track the location continuously. When the tower has to assign jobs to the Loader, they will release instruction according to the location of the loader. It leads to confusion in assigning jobs to the right Loader.

\section{Vehicles Entry to the Terminal}

Limited permission is granted for vehicles to enter the terminal. Every vehicle which needs to enter the terminal has a pass to access to the terminal. The pass has to be checked by a security guard before entering the terminal. By using an RFID tag as a pass, the access of a vehicle can be automated.

With the challenges mentioned above, it is proposed to use RFID to track vehicles with the following two objectives:

- To design a system for tracking the location of both internal tractors and patrol cars in the terminal. This system includes the physical setup of RFID equipment in the yard and the software requirement 
- To facilitate the operators in monitoring the traffic condition of the terminal (i.e. to check the number of vehicles in a specific area at a particular time) and assigning jobs to patrol car drivers effectively, which reduces the time in finding the drivers

\subsection{RFID Hardware selection}

There are 4 set of RFID readers and tags considered in the experiment. Only one set of equipment will be used in the experiment since the aim of the experiment is to know whether RFID technology is usable in the container terminal. So, it is necessary to find a balance between cost and read range. The specifications of different equipment are listed in the Table 2.

\begin{tabular}{|c|c|c|c|c|}
\hline Equipment & $\begin{array}{c}\text { AI1611 SmartPass } \\
\text { Reader with } \\
\text { AT5547 TollTag }\end{array}$ & $\begin{array}{c}\text { ALR-2850 Alien } \\
\text { Reader }\end{array}$ & RCG-CR210 & $\begin{array}{c}\text { i-Card Mobile } \\
\text { Interrogator(Hand } \\
\text {-held) }\end{array}$ \\
\hline Distance & $5-6 m$ (Outdoor) & 30m(Indoor) & $5-20 m$ & $100 \mathrm{~m}$ (Indoor) \\
\hline Price $(\mathrm{HK} \$)$ & $42000+290=42290$ & $22500+235=22735$ & $15800+180=15980$ & $\begin{array}{l}11900+ \\
460=12360\end{array}$ \\
\hline Frequency & $2.45 \mathrm{GHz}$ & $2.45 \mathrm{GHz}$ & $2.4 \mathrm{GHz}$ & $915 \mathrm{MHz}$ \\
\hline Connection & $\begin{array}{l}\text { RS-232, RS-422 or } \\
\text { Wiegand- } \\
\text { compatible host } \\
\text { interface }\end{array}$ & $\begin{array}{l}\text { RS232,9-pin, Sub } \\
\text { D(female) }\end{array}$ & $\begin{array}{l}\text { RS232, 4-pin, } \\
\text { Wiegand 26bits }\end{array}$ & $\begin{array}{l}\text { PCMCIA, RS-232, } \\
\text { JTAG via PGM } 15 \\
\text { connector }\end{array}$ \\
\hline $\begin{array}{l}\text { Operating } \\
\text { temperature }\end{array}$ & $-40^{\circ} \mathrm{C} \rightarrow 50^{\circ} \mathrm{C}$ & $-20^{\circ} \mathrm{C} \rightarrow 55^{\circ} \mathrm{C}$ & $-40^{\circ} \mathrm{C} \rightarrow 80^{\circ} \mathrm{C}$ & $-20^{\circ} \mathrm{C} \rightarrow 60^{\circ} \mathrm{C}$ \\
\hline Weight & $7.2 \mathrm{~kg}$ & $2 \mathrm{~kg}$ & - & $0.005 \mathrm{~kg}$ \\
\hline Dimension & $\begin{array}{l}38.1 \times 41.7 \times \\
10.2 \mathrm{~cm}\end{array}$ & $\begin{array}{l}17.85 \times 25.5 \times \\
5.1 \mathrm{~cm}\end{array}$ & $12.4 \times 7.6 \times 2.3 \mathrm{~cm}$ & $86 \times 54 \times 5 \mathrm{~mm}$ \\
\hline $\begin{array}{l}\text { Power } \\
\text { consumption }\end{array}$ & $90-264$ VAC & $\begin{array}{l}\text { 12VDC, 2A, } 25 \\
\text { Watts }\end{array}$ & 7-13 VDC & $5 \operatorname{VDC}(+/-5 \%)$ \\
\hline Data rate & $*$ & $16 \mathrm{kbits} / \mathrm{s}$ & $250 \mathrm{kbits} / \mathrm{s}$ & $115.2 \mathrm{kbits} / \mathrm{s}$ \\
\hline
\end{tabular}

Table 2. Comparison of different RFID equipment

There are quite a number of similarities among these readers. All the four readers operate at Ultra High or Microwave Frequency. On the other hand, the read range of all the readers is quite similar, although some of the readers have a read range up to $100 \mathrm{~m}$. The outdoor performance of all the readers will decrease due to numerous reasons. At the same time, the operating temperatures are also similar among those readers. All the four readers can work between $-20^{\circ} \mathrm{C}$ and $50^{\circ} \mathrm{C}$ which cover the normal outdoor temperatures in Southern China. The general description of each RFID component is discussed below:

- The SmartPass Reader has an average performance. The advantage of the reader is that it is an all-in-one reader. That is, the antenna and the reader are in the same unit. Since the reader is placed in a limited area in a vehicle, the all-in-one reader can save space in the vehicle. However, there 
are some disadvantages of using this reader. First of all, the read range is not far enough, only about 5 to 6 meters. The all-in-one reader implies larger and heavier equipment. At last, the most important disadvantage of this reader is that it is the most expensive

- The advantage of the Alien reader is that this reader is not as heavy as the SmartPass reader. However, it is not an all-in-one reader and the antenna and reader are not small enough, so the vehicle needs more space for this equipment. The price of this reader is average and the read range of this reader is quite good

- The read range of RCG-CR210 is average at about 5-20 m. The size of the reader is small, compared with other readers except the card reader. The most attractive advantage of this reader is the price, which is around 16000 Hong Kong dollars

- The Card Mobile Interrogator is a handheld reader, that is, the reader is equipped with a mobile device. Although it would be very convenient to carry from one place to another as the size and the weight is less compared to other readers, it does not have an obvious advantage in this situation except in space saving. It would be better if the reader could be mounted tightly in a fixed location. The Card mobile Interrogator cannot fulfill this requirement. Another problem for the reader is that the read range is too large. Since the application is to track the vehicle location, it is not suitable to have a read range so large

In comparing the above 4 readers, RCG-CR210 is selected because of the following reasons:

- The price is relatively cheap. As it is very expensive to implement a RFID system in a container terminal, the cost is the major concern of the system. So, cheaper RFID equipment will have advantages over the others. The RCG-CR210 is relatively cheap compared to other reader sets

- The read range is acceptable. A longer read range does not necessarily mean having a advantage over the others. A longer read range reader covers a large area, and means that it cannot track vehicles to a detailed position but only inside a larger range of area. However, for a short range reader, it is not enough to cover only the cross-section of a road, hence a suitable read range is required. The read range of the RCG-CR210 is 
claimed at about $20 \mathrm{~m}$, so it should be suitable in the container terminal environment

- The size and weight are relatively lower. As stated above, a whole set of equipment is needed to be placed in the vehicle, however the space in a vehicle is limited and not very large. So, it is important that the equipment should not be too large. The RCG-CR210 is not as large as the other readers

\subsection{Experiment 1: Distance test}

The distance test is aimed at finding out the longest read range of the RF communication in the terminal. It helps to determine the setup of the reader and tag in the terminal. This test took place in several areas, near the sea, the free area and near the containers. This is to find out the difference in the read range in different container terminal environments. Also, the entire tests took place where traffic was light. A brief description of the three areas follows:

- Free area. In the free area, there are no buildings or other construction work near the test area. so, there is no physical disturbance within the testing environment

- Near Containers. The tests are carried out in the light container yard. Figure 4 depicts the tests in the actual environment

- Near Sea Side. The tests are carried out on the pier side, with the sea just beside the testing area. Quay Craves are near the testing area

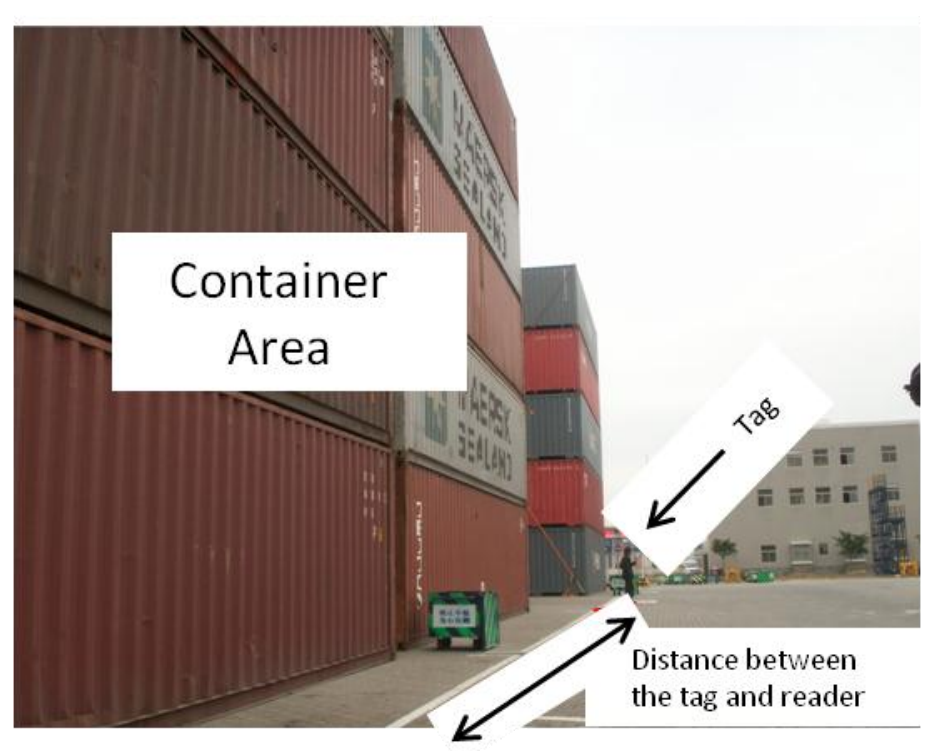

Figure 4. Setup of distant test in containers area 


\section{Procedures}

For easy testing, the reader is placed in a fixed location and the tag is carried manually. The testing procedures are described as follows:

Step 1. Tag stand placed in the yard

Step 2. The vehicle stationed $5 \mathrm{~m}$ away from the tag

Step 3. Software used to trace the tag for 1 minute

Step $4 . \quad$ See the percentage of successful communication

Step 5. Repeat Steps 1-4 for five times to get more data

Step $6 . \quad$ Increase the distance by $5 \mathrm{~m}$ and repeat the above

Step 7. The experiment is stopped when there is no signal for the 2 tests distances

\subsection{Experiment 2: Speed test}

It is aimed to find out, when the velocity increases, if the RF communication will be successful.

\section{Procedures}

Step 1. Place tag stand in the yard, near the end of the road

Step 2. Drive the vehicle passed the tag at $5 \mathrm{~km} / \mathrm{h}$

Step 3. Using software to trace the tag. Test 10 times

Step 4. Note the percentage of successful communications

Step 5. Increase the speed by $5 \mathrm{~km} / \mathrm{h}$ and repeat the above process

The speed limit of the terminal is $40 \mathrm{~km} / \mathrm{h}$, so the test will stop at $40 \mathrm{~km} / \mathrm{h}$

\subsection{Experiment 3: Penetration}

In the container terminal, there are a lot of operations and many machines and vehicles are running. RF waves may be easily blocked by these machines and vehicles and so there may be a failure of communication. This test is aimed at finding out if the RF communication can have penetration behind vehicles and containers. Figure 5 shows the design of the penetration test. 


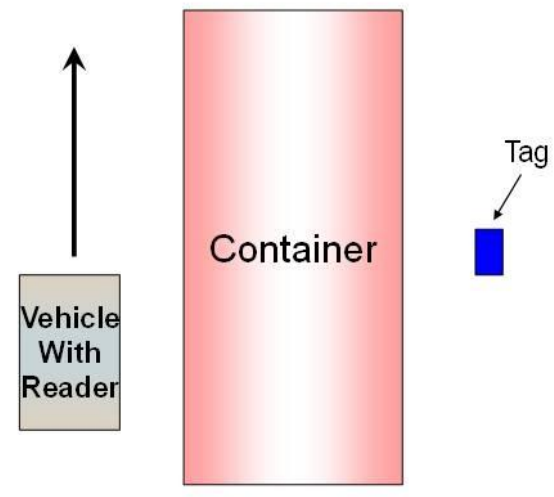

Figure 5. Setup of penetration test

\section{Procedures}

Step 1. Place tag on one side of the container

Step 2. Drive the vehicle on the other side of the container

Step $3 . \quad$ See if the communication occurs

Step 4. Increase the number of containers, and repeat steps 1-3

\subsection{Experiment 4: Field of service test}

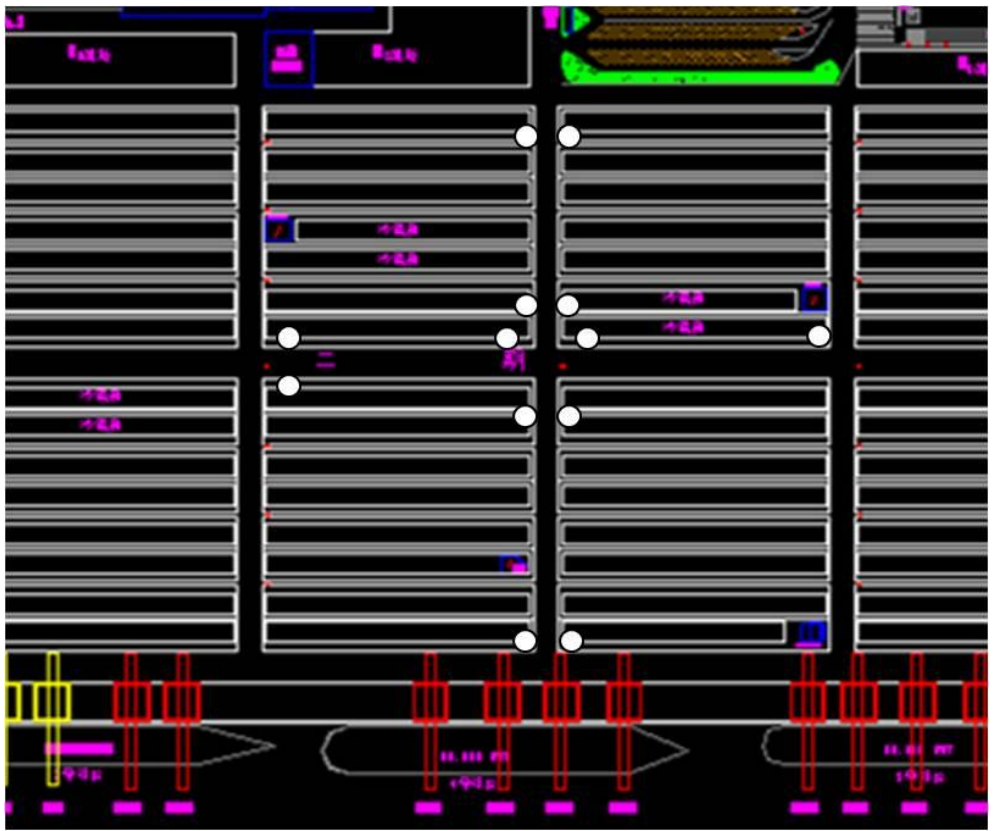

Figure 6. Location of placing tags

In the second stage, there is a trial run, which is, placing tags in different locations to simulate the real operation. The area selected for a trial run is about one- 
seventh of the total area of the terminal. In this simulation, the test is carried out in a small area; also, it is not be the same as the real operation. That is, the tag and vehicle will only be tracked in the "large road". Figure 6 shows the location of tags within the test area.

\section{Procedures}

Step 1. Place tags in appropriate locations (Figure 7)

Step 2. Drive vehicle through the test area

Step 3. Record the detected tag and the tag intended to be read

Step 4. Compare the result

Step 5. $\quad$ Find out the percentage of read tag

Step 6. $\quad$ Find out the failure point and change the setting

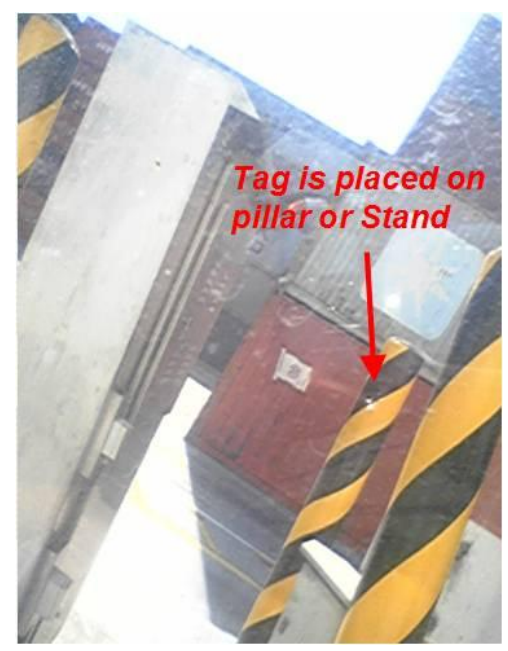

Figure 7. Tags are placed on pillar or stand at corner near crossroad

\section{Retrieving Demo Program}

As the purpose of this stage of the experiment is to simulate the real operation, a retrieving software is used to track the data from the database. By using the Retrieving Demo program, a user can input the ID of the vehicle that he/she wants to query, then, the software will direct the user to the related database to get the latest record of the location of the vehicle. Afterwards, the software shows the latest information to the client interface. The web page refreshes itself every $5 \mathrm{~s}$ so the information would be the most updated one. An example of the tracking process is shown in Figure 8. A user inputs the vehicle number to be tracked, and 
after a query to the database, the screen shows the location of the particular vehicle.

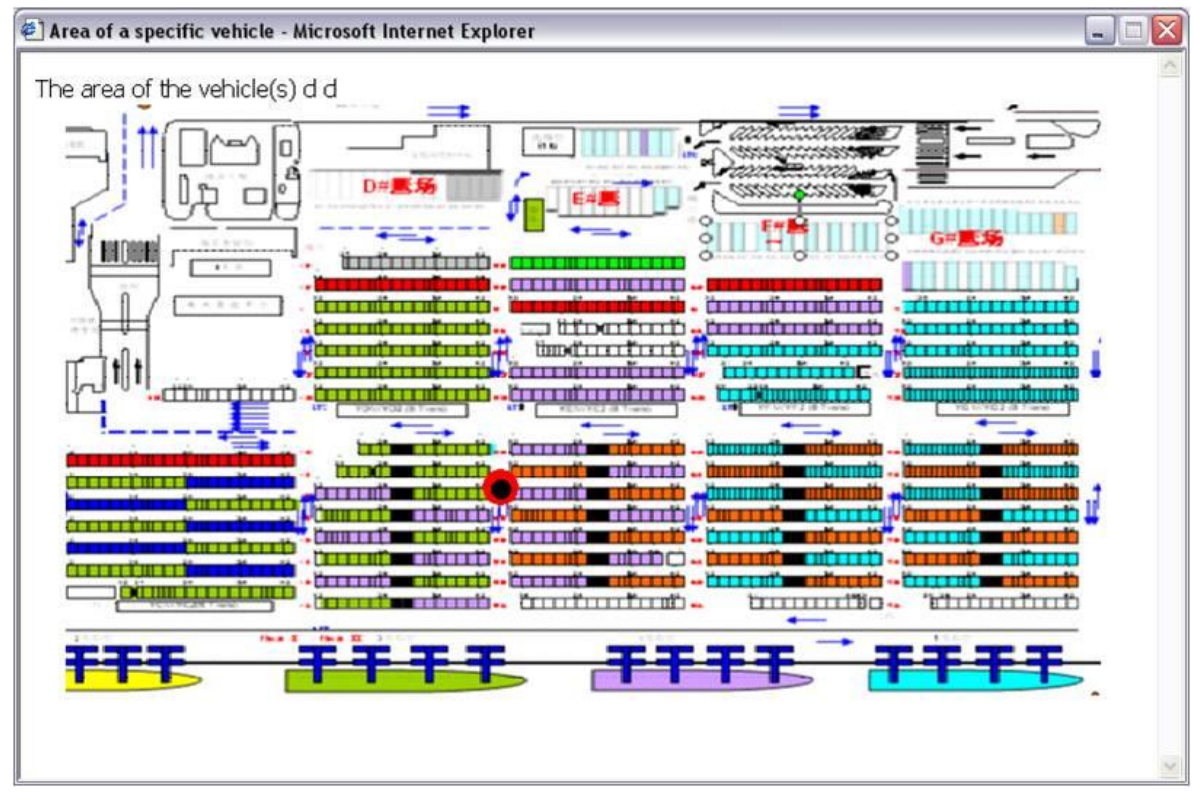

Figure 8. Interface for vehicle location

\section{Performance and discussion of distance test}

The results obtained in the distance tests are shown in Table 3, while the averages of the trial run result for different areas are shown in Figure 9. Furthermore, the results also graphically show the average performance of the RFID communication in different area as a comparison.

\begin{tabular}{|c|r|r|r|}
\hline $\begin{array}{r}\text { Specific } \\
\text { Environment }\end{array}$ & & & \\
& & & \\
& & & \\
Distance $(\mathrm{m})$ & & & \\
\hline 5 & $100.00 \%$ & $100.00 \%$ & $100.00 \%$ \\
\hline 10 & $70.00 \%$ & $100.00 \%$ & $100.00 \%$ \\
\hline 15 & $33.33 \%$ & $100.00 \%$ & $80.00 \%$ \\
\hline 20 & $28.33 \%$ & $100.00 \%$ & $55.00 \%$ \\
\hline 25 & $11.67 \%$ & $100.00 \%$ & $58.33 \%$ \\
\hline 30 & $0.00 \%$ & $100.00 \%$ & $26.67 \%$ \\
\hline 35 & $6.67 \%$ & $98.33 \%$ & $8.33 \%$ \\
\hline 40 & $3.33 \%$ & $95.00 \%$ & $0.00 \%$ \\
\hline 45 & $0.00 \%$ & $41.67 \%$ & $0.00 \%$ \\
\hline 50 & $0.00 \%$ & $10.00 \%$ & $0.00 \%$ \\
\hline 55 & $0.00 \%$ & $0.00 \%$ & $0.00 \%$ \\
\hline & \multicolumn{3}{|r}{} \\
\hline
\end{tabular}

Table 3. Results of distance test 


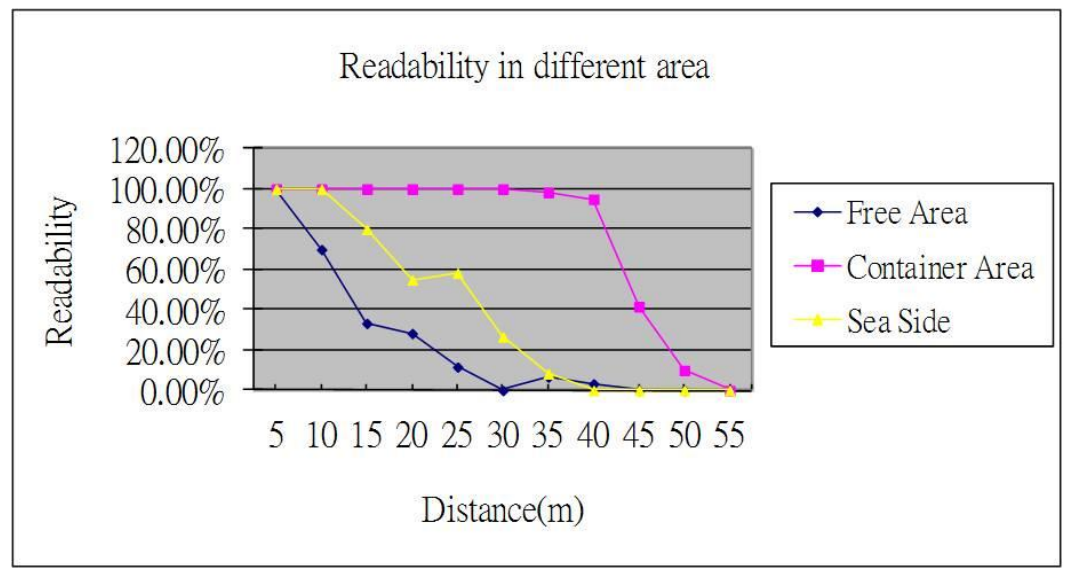

Figure 9. Relationships between Readability and Distance in different area

\section{Free Area}

Figure 10 shows the readability of each trial. The $100 \%$ readability only occurs at the $5 \mathrm{~m}$ distance and the readability drop significantly after $10 \mathrm{~m}$. This test reflects the "true" ability of the reader as there is no disturbance near the test area. At distances of $35 \mathrm{~m}$ and $40 \mathrm{~m}$, few communications occurred; one of the possible reasons of this is the small size of data.

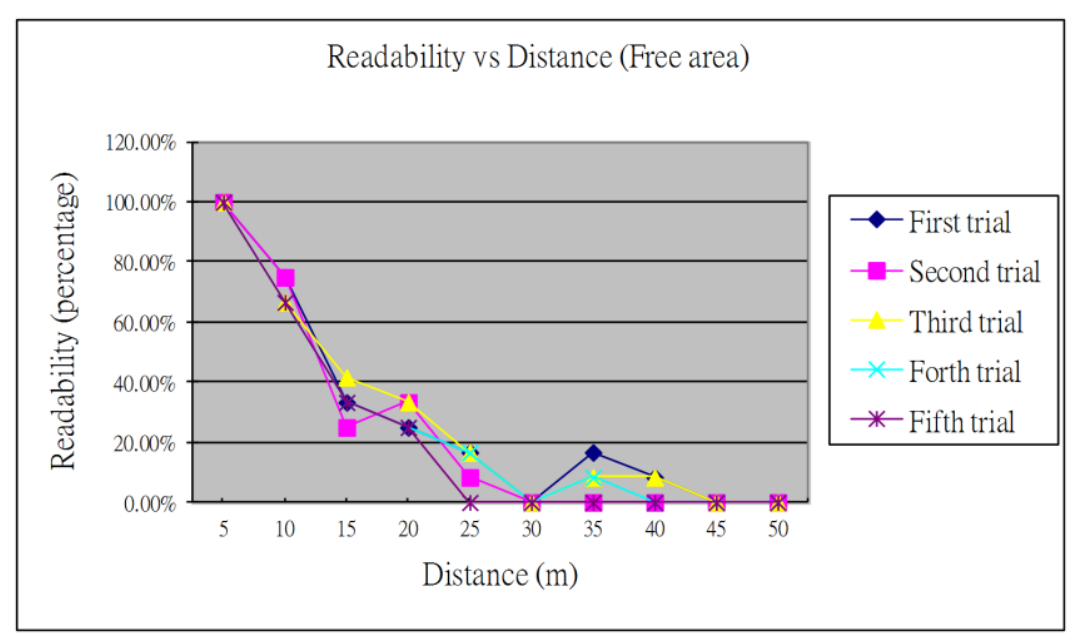

Figure 10. Relationship between readability and distance in free area

As the readability of the RFID communication drops significantly between $5 \mathrm{~m}$ to 15 $\mathrm{m}$, an additional test was carried out in order to know how the readability changes between the ranges. It is important to find out this data because this range is critical as most of the road widths are similar to twice this range. The results of the additional test are shown in Figure 11. 


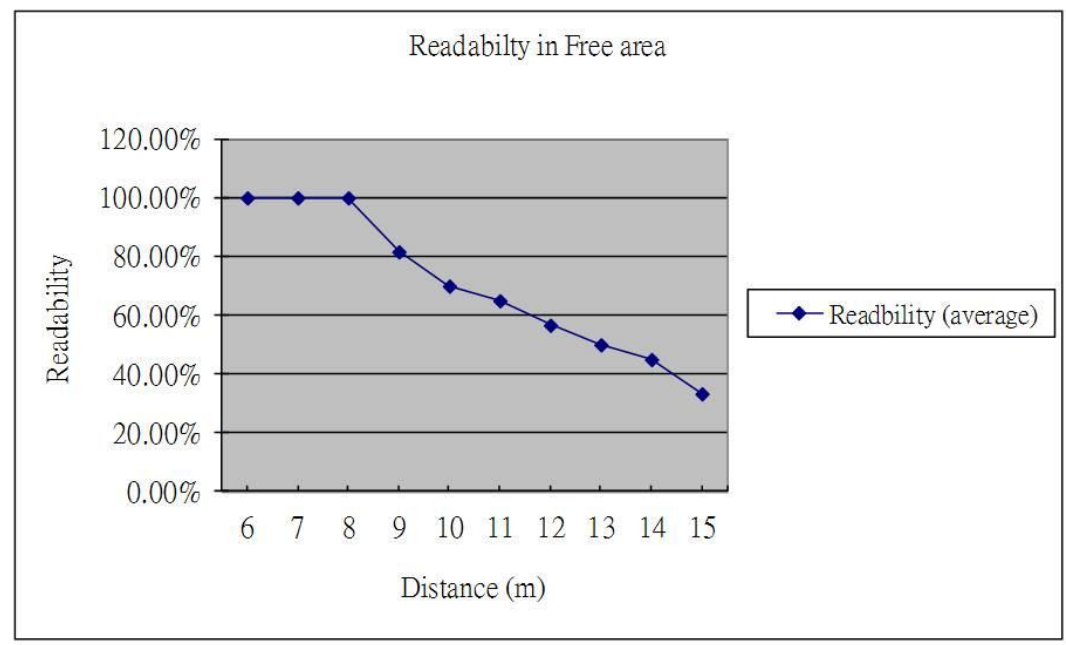

Figure 11. Readability in free area between the range of $6-15 \mathrm{~m}$

As from the additional data, it is found that the readability is still in $100 \%$ at $8 \mathrm{~m}$ while it starts to drop at $9 \mathrm{~m}$ and thereafter drops continuously.

\section{Near Container Area}

Figure 12 shows the readability of each of the trials. It is surprisingly to see that the readability is $100 \%$ until $30 \mathrm{~m}$ when the test is carried out in this area. This result is very encouraging as it shows that the use of RFID in a normal container environment is possible. Despite the encouraging result, the readability drops significantly at $45 \mathrm{~m}$. One of the possible reasons for the encouraging result is the reflection of radio waves from the container. The reflection of radio waves from the container makes the signal more concentrated in the area. As the range of $40 \mathrm{~m}$ and $45 \mathrm{~m}$ is not critical as it exceed the longest width of a road, additional tests are not needed.

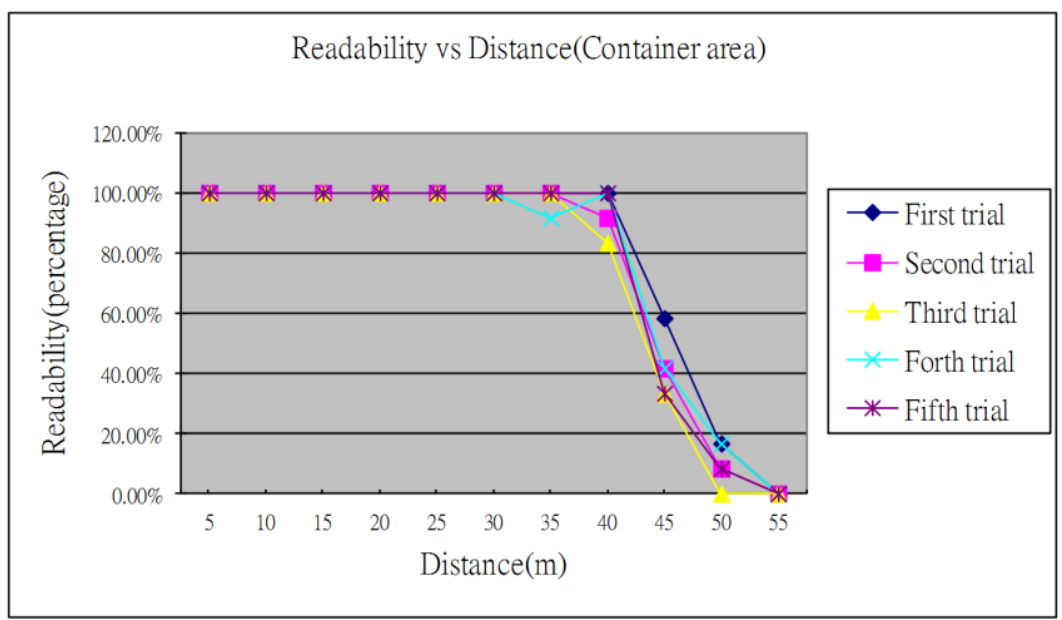

Figure 12. Relationship between readability and distance in container area 


\section{Near Sea Side}

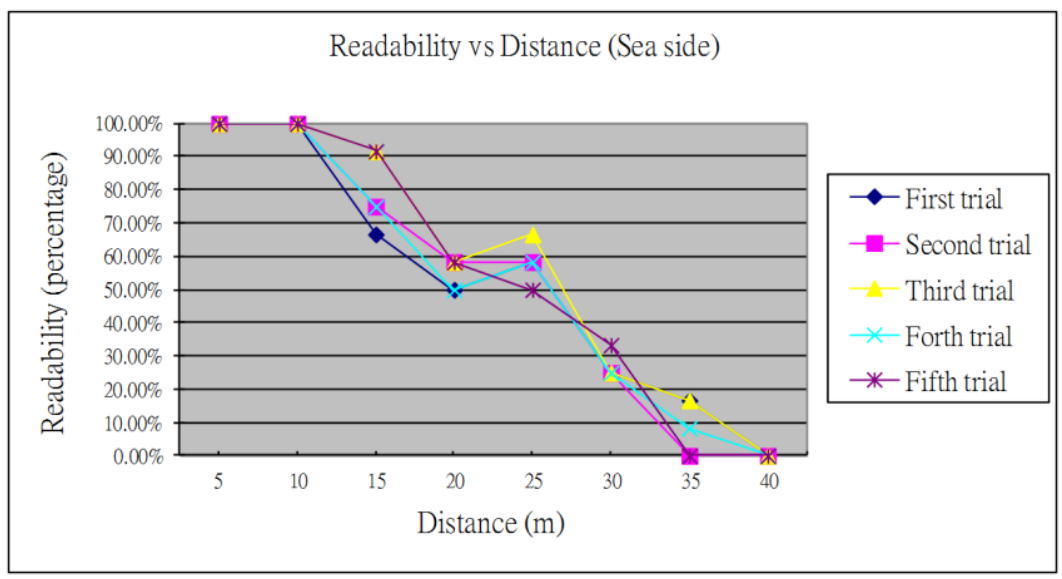

Figure 13. Relationship between readability and distance in Sea Side

Figure 13 shows the readability of each trial. The result of this test is similar to the free area test. The readability drops steadily after $10 \mathrm{~m}$. However, some the trial readability readings increase at a distance of $25 \mathrm{~m}$. One of the reasons is that the communication in this environment only drops gradually, so the result of data may be similar within close distances. Another reason is that the quay crane at the pier side affects the test result.

As there is a drop between the range of $10 \mathrm{~m}-20 \mathrm{~m}$, an additional test was carried out and the results are shown in Figure 14. The readability in this range drops gradually, starting from $12 \mathrm{~m}$ and meets the $50 \%$ readability at $20 \mathrm{~m}$.

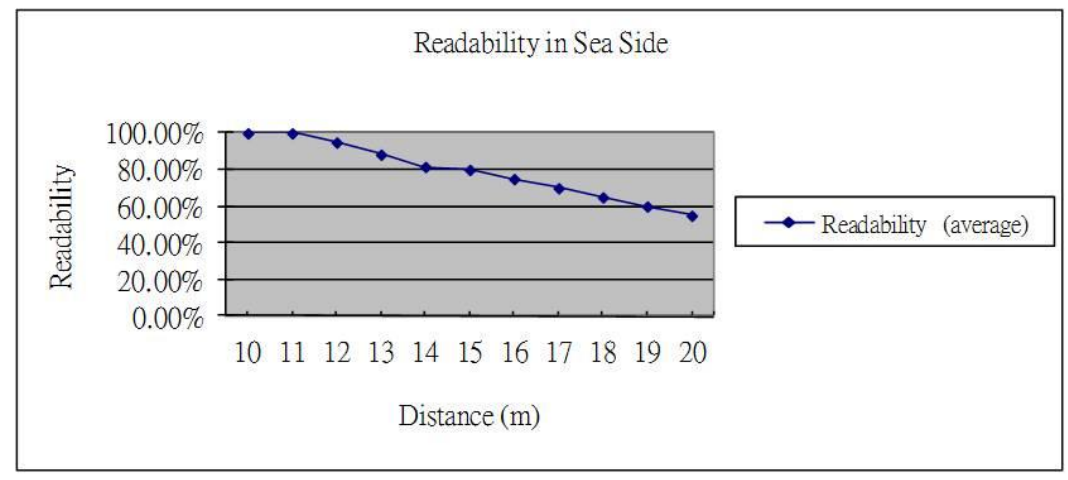

Figure 14. Relationship between readability and distance in Sea Side

\section{Findings}

From the above results, it is found that RFID communication is good in the container areas which occupy almost of the area in the container terminal. However, in other areas, such as the sea side and the free area, the performance is 
not so good and $100 \%$ readability is only achieved at $5 \mathrm{~m}$ and $10 \mathrm{~m}$ in the free area and the sea side respectively. So, a special arrangement for tagging is necessary in these areas, more tags are necessary to put on such area.

\subsection{Speed test}

The result of the speed test is encouraging. The RF reader can have $100 \%$ readability within the speed limit $(40 \mathrm{~km} / \mathrm{h})$ in the terminals, as shown in Figure 15. As the test is carried out both in the nearest lane and the farthest lane of a road, the RFID communication can operate well in regard to speed.

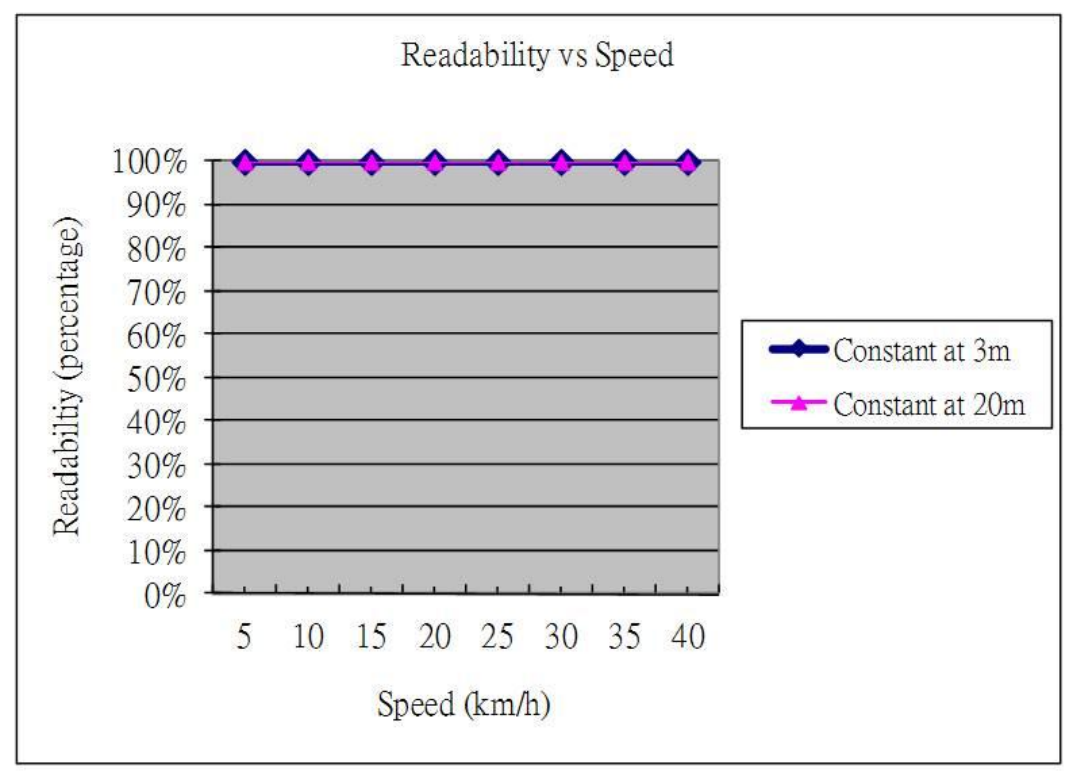

Figure 15. Relationships between readability and speed

\subsection{Penetration test}

Figure 16 illustrates the result of the penetration test. It is found that the reader cannot read a tag behind the container. It means that the communication cannot pass through containers or internal tractors. If a tractor stays between the tags and the reader in the vehicle, the communication is blocked by the tractor. Because of this, special arrangements are necessary to solve the problem. One of the suggestions is to put an extra tag at the center of the road. 


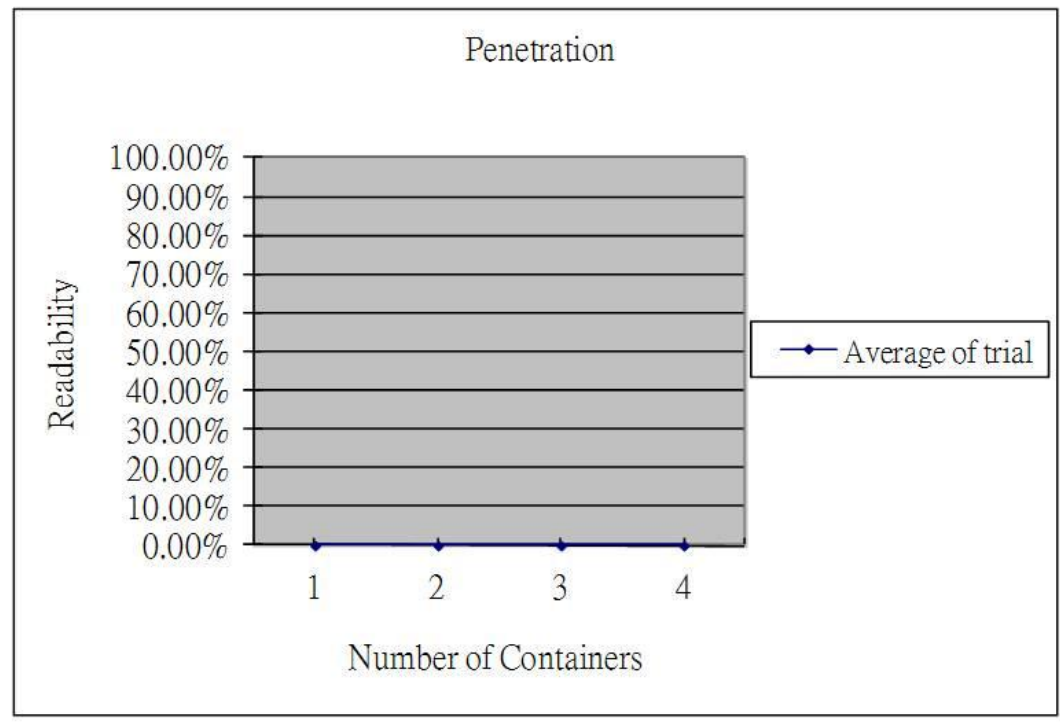

Figure 16. Relationship readability and distance in cross road

\subsection{Short conclusion for first stage}

Despite the fact that the RFID communication of the selected reader did not work well in the free area and near the sea side in the distance test, the overall result of the first stage experiments shows that it is possible to use RFID to track vehicle in the terminal. As most of the environment in the terminals like the one in the "Near Container test", RFID communication can be carried out in most of the areas in the container terminal. It is suggested that extra tests should carried out in order to compare the "real operation" of different readers. Based on the above results, a second stage experiment is carried out.

\subsection{Field of service test}

Table 4 illustrates the result of the second stage test. The tags which represent the same area are marked with the same color (except the white color). As the vehicle is said to be entering an area if one of the tag is detected, only detecting one of the tag is deemed to be a successful record, as another tag may be blocked by another vehicle or machine. 


\begin{tabular}{|c|c|c|c|c|c|c|c|c|c|c|c|c|}
\hline \multirow{2}{*}{$\begin{array}{l}\text { Tag Cycle } \\
\text { Tag } \\
\text { Numbers }\end{array}$} & \multicolumn{10}{|c|}{ Test cycle } & \multirow{2}{*}{$\begin{array}{c}\text { Readability } \\
\text { per tag }\end{array}$} & \multirow{2}{*}{$\begin{array}{c}\text { Readability } \\
\text { per area }\end{array}$} \\
\hline & 1 & 2 & 3 & 4 & 5 & 6 & 7 & 8 & 9 & 10 & & \\
\hline 15 & $\checkmark$ & $\checkmark$ & $\checkmark$ & $\checkmark$ & $\checkmark$ & $x$ & $x$ & $\checkmark$ & $x$ & $x$ & $60 \%$ & $60 \%$ \\
\hline 9 & $\checkmark$ & $\checkmark$ & $\checkmark$ & $\checkmark$ & $\checkmark$ & $\checkmark$ & $\checkmark$ & $\checkmark$ & $\checkmark$ & $\checkmark$ & $100 \%$ & \multirow{2}{*}{$100 \%$} \\
\hline 10 & $\checkmark$ & $O$ & $\checkmark$ & $\checkmark$ & 0 & $\checkmark$ & 0 & $\checkmark$ & $\checkmark$ & $\checkmark$ & $70 \%$ & \\
\hline 5 & $x$ & $\checkmark$ & 0 & $\checkmark$ & 0 & $\checkmark$ & $\checkmark$ & $\checkmark$ & $O$ & $\checkmark$ & $60 \%$ & \multirow{2}{*}{$90 \%$} \\
\hline 6 & $x$ & $\checkmark$ & $\checkmark$ & $\checkmark$ & $\checkmark$ & 0 & $\checkmark$ & $\checkmark$ & $\checkmark$ & $\checkmark$ & $80 \%$ & \\
\hline 7 & $\checkmark$ & $\checkmark$ & $\checkmark$ & $\checkmark$ & $\checkmark$ & $O$ & $\checkmark$ & $O$ & $O$ & $O$ & $60 \%$ & \multirow{2}{*}{$100 \%$} \\
\hline 8 & $\checkmark$ & $O$ & $\checkmark$ & $\checkmark$ & $\checkmark$ & $\checkmark$ & $O$ & $\checkmark$ & $\checkmark$ & $\checkmark$ & $80 \%$ & \\
\hline 11 & $\checkmark$ & $\checkmark$ & $\checkmark$ & $\checkmark$ & $\checkmark$ & $\checkmark$ & $\checkmark$ & $\checkmark$ & $\checkmark$ & $\checkmark$ & $100 \%$ & \multirow{2}{*}{$100 \%$} \\
\hline 12 & $O$ & $\checkmark$ & $\checkmark$ & 0 & $O$ & $O$ & O & $O$ & $O$ & $O$ & $20 \%$ & \\
\hline 13 & $\checkmark$ & $x$ & $\checkmark$ & 0 & $\checkmark$ & 0 & $\checkmark$ & $\checkmark$ & $\checkmark$ & 0 & $60 \%$ & \multirow{2}{*}{$90 \%$} \\
\hline 14 & $\checkmark$ & $x$ & $\checkmark$ & $\checkmark$ & $\checkmark$ & $\checkmark$ & $\checkmark$ & $\checkmark$ & $\checkmark$ & $\checkmark$ & $90 \%$ & \\
\hline 1 & $\checkmark$ & $\checkmark$ & $\checkmark$ & $\checkmark$ & $\checkmark$ & $\checkmark$ & $\checkmark$ & $\checkmark$ & $\checkmark$ & $\checkmark$ & $100 \%$ & $100 \%$ \\
\hline 3 & $\checkmark$ & $\checkmark$ & $\checkmark$ & $\checkmark$ & $\checkmark$ & $\checkmark$ & $\checkmark$ & $\checkmark$ & $\checkmark$ & $\checkmark$ & $100 \%$ & $100 \%$ \\
\hline
\end{tabular}

Table 4. Result of Second Stage test

By combining the results, it is found that only one of the tags had $60 \%$ readability. This is due to the communication being blocked by another machine in the period from 6-10 am. Another problem is that there is wrong communication in the cross road area. Some of the detection is incorrect, that is, not detecting the correct tags. Figure 17 shows the tags that are detected wrongly, and are marked in red.

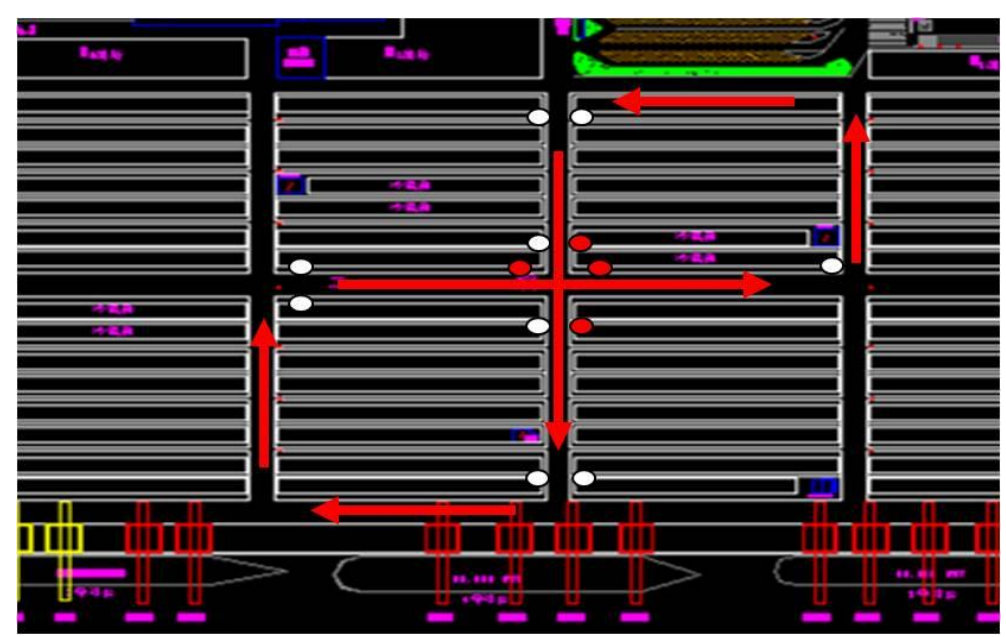

Figure 17. Wrongly detected tags

It is noted that the system will only accept $100 \%$ correct communication and there is no allowance for unsuccessful communication. So, a suggested system is necessary to follow the setup method of the tag " $9,7,8,11,12,1,3$ ". These sets of tags are placed at the stand beside the corner of the road or the stand between containers. However, as the tag number " 15 " is blocked by a machine for a long 
period of time and no communication occurred, some suggestions are made in response to this problem.

\subsection{Suggestions for system improvement}

- In order to solve the problem of blocked communication, it is suggested that tags should be placed at the two sides of the road and at the center of the road if the road has more than 4 lanes (more than one lane in the same direction). This can prevent the communication being blocked by other vehicles or machines. However, this would increase the cost of the implementation as extra construction is necessary in order to set up tags in the center of a road

- In order to avoid the incorrect detection of tags, it is suggested that tags in the cross road area should not be placed near the corner of the road. Instead, tags should be placed at least $30 \mathrm{~m}$ away from the cross road. By doing so, it can ensure tags will not be detected incorrectly. Also, it can also ensure that the tags can be detected after entering into a specific area

- Another possible way to solve the incorrect communication is to fine tune the read range of the antenna. Tuning the read range of the antennas shorter can help to prevent the incorrect communication, and antennas can be kept in place in the area near the cross road. On the other hand, the reading area can be more specific as the read range is shorter. However, the read range should not be less than $7 \mathrm{~m}$ i.e. 2 lanes of a road

\subsection{Experiment for validation of suggestions}

In order to check whether the suggestions stated above are correct, some extra experiments are carried out. However, there are no extra experiments for point 3 and 4 as they are related to the specification of the reader. The validation experiments are on points 1 and 2 only.

\section{Validation Experiment}

In this experiment, the procedure is the same with the second stage with the difference in the placing of the tags. Additional tags are placed in the location where that readability is low. On the other hand, the tags are all placed in the same way with the tags which get $100 \%$ readability in the "FIELD OF SERVICE TEST". That is, placing these tags on the stand away from corners at least $30 \mathrm{~m}$. Figure 18 shows the location of the extra tags which are marked in red. 


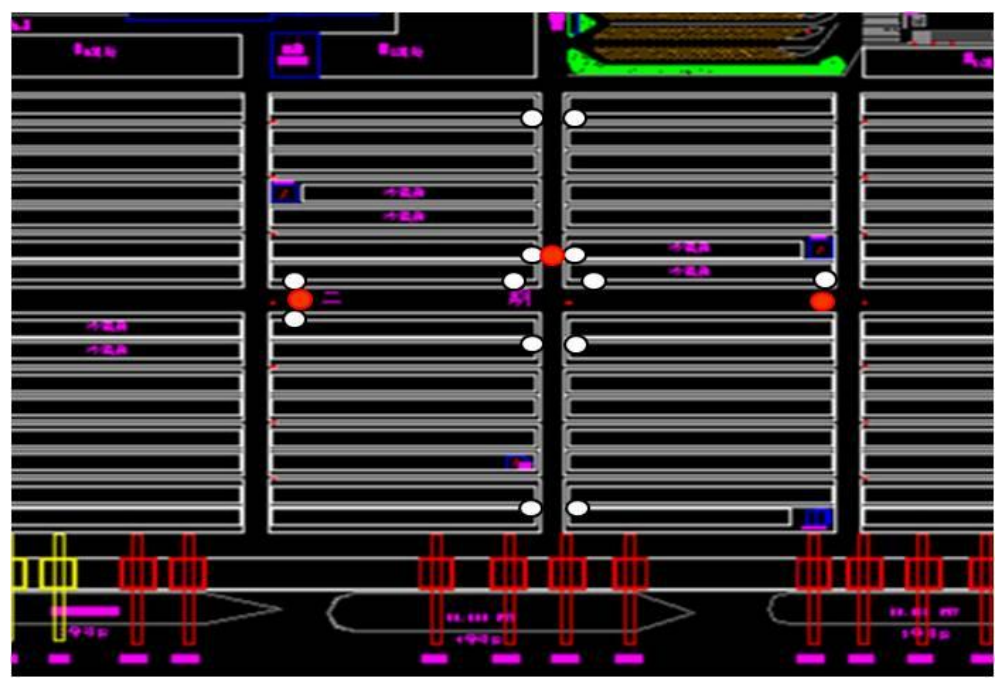

Figure 18. Location of tags in validation experiment

Table 5 lists the results of the validation test. Additional tags are added (tag numbers $17,18,19)$ in the center of some of the roads. In addition, tags are placed on stands and avoid disturbances such as large machine. The tags are also placed away from the corners of the road to prevent incorrect communication.

\begin{tabular}{|c|c|c|c|c|c|c|c|c|c|c|c|c|}
\hline \multirow{2}{*}{ Tag Cycle } & \multicolumn{10}{|c|}{ Test cycle } & \multirow{2}{*}{$\begin{array}{l}\text { Readability } \\
\text { per tag }\end{array}$} & \multirow{2}{*}{$\begin{array}{l}\text { Readability } \\
\text { per area }\end{array}$} \\
\hline & 1 & 2 & 3 & 4 & 5 & 6 & 7 & 8 & 9 & 10 & & \\
\hline 15 & $\checkmark$ & $\checkmark$ & $O$ & $\checkmark$ & $\checkmark$ & $\checkmark$ & $\checkmark$ & $\checkmark$ & $\checkmark$ & $\checkmark$ & $90 \%$ & \multirow{2}{*}{$100 \%$} \\
\hline 17 & $\checkmark$ & $\checkmark$ & $\checkmark$ & $\checkmark$ & $\checkmark$ & $\checkmark$ & $\checkmark$ & $O$ & $\checkmark$ & $\checkmark$ & $90 \%$ & \\
\hline 9 & $\checkmark$ & $\checkmark$ & $\checkmark$ & $\checkmark$ & $\checkmark$ & $O$ & $\checkmark$ & $\checkmark$ & $\checkmark$ & $\checkmark$ & $90 \%$ & \multirow{2}{*}{$100 \%$} \\
\hline 10 & $\checkmark$ & $\checkmark$ & $\checkmark$ & $\checkmark$ & $\checkmark$ & $\checkmark$ & $\checkmark$ & $\checkmark$ & $O$ & $\checkmark$ & $90 \%$ & \\
\hline 5 & $\checkmark$ & $\checkmark$ & $\checkmark$ & $\checkmark$ & $\checkmark$ & $\checkmark$ & $O$ & $\checkmark$ & $\checkmark$ & $\checkmark$ & $90 \%$ & \multirow{3}{*}{$100 \%$} \\
\hline 18 & $\checkmark$ & $\checkmark$ & $\checkmark$ & $\checkmark$ & $\checkmark$ & $\checkmark$ & $\checkmark$ & $\checkmark$ & $\checkmark$ & $\checkmark$ & $100 \%$ & \\
\hline 6 & $\checkmark$ & $O$ & $\checkmark$ & $\checkmark$ & $O$ & $\checkmark$ & $\checkmark$ & $\checkmark$ & $\checkmark$ & $\checkmark$ & $80 \%$ & \\
\hline 7 & $\checkmark$ & $\checkmark$ & $\checkmark$ & $\checkmark$ & $\checkmark$ & $\checkmark$ & $\checkmark$ & $O$ & $O$ & $\checkmark$ & $80 \%$ & \multirow{2}{*}{$100 \%$} \\
\hline 8 & $\checkmark$ & $\checkmark$ & $\checkmark$ & $\checkmark$ & $\checkmark$ & $\checkmark$ & $\checkmark$ & $\checkmark$ & $\checkmark$ & $\checkmark$ & $100 \%$ & \\
\hline 11 & $\checkmark$ & $\checkmark$ & $\checkmark$ & $\checkmark$ & $\checkmark$ & $\checkmark$ & $\checkmark$ & $\checkmark$ & $\checkmark$ & $\checkmark$ & $100 \%$ & \multirow{2}{*}{$100 \%$} \\
\hline 12 & $\checkmark$ & $\checkmark$ & $\checkmark$ & $\checkmark$ & $\checkmark$ & $O$ & $O$ & $\checkmark$ & $O$ & $\checkmark$ & $70 \%$ & \\
\hline 13 & $\checkmark$ & $\checkmark$ & $O$ & O & $\checkmark$ & $\checkmark$ & $O$ & $\checkmark$ & $\checkmark$ & O & $60 \%$ & \multirow{3}{*}{$100 \%$} \\
\hline 19 & $\checkmark$ & $\checkmark$ & $\checkmark$ & $\checkmark$ & $\checkmark$ & $\checkmark$ & $\checkmark$ & $\checkmark$ & $\checkmark$ & $\checkmark$ & $100 \%$ & \\
\hline 14 & $\checkmark$ & $\checkmark$ & $\checkmark$ & $\checkmark$ & $\checkmark$ & $O$ & $\checkmark$ & $\checkmark$ & $\checkmark$ & $\checkmark$ & $90 \%$ & \\
\hline 1 & $\checkmark$ & $\checkmark$ & $\checkmark$ & $\checkmark$ & $\checkmark$ & $\checkmark$ & $\checkmark$ & $\checkmark$ & $\checkmark$ & $\checkmark$ & $100 \%$ & $100 \%$ \\
\hline 3 & $\checkmark$ & $\checkmark$ & $\checkmark$ & $\checkmark$ & $\checkmark$ & $\checkmark$ & $\checkmark$ & $\checkmark$ & $\checkmark$ & $\checkmark$ & $100 \%$ & $100 \%$ \\
\hline
\end{tabular}

Table 5. Results of validation test

Despite one of the tags only having $60 \%$ readability, all the areas have $100 \%$ readability when a vehicle enters an area. That is, the vehicle is wholly tracked in the test period. As a conclusion for this chapter, it is found that the FRID system is possible to be implemented in a container terminal with specific settings, such as placing more tags to track some locations and not putting them corners. 


\section{Cost evaluation}

Investment cost is one of the significant factors affecting the implementation of RFID systems (Ngai, et al., 2010). In this study, the total setup cost (including the readers, tags, software, etc.) is around $\mathrm{HK} \$ 6.5$ millions to track and trace 600 vehicles (with $100 \%$ tag readability). Although the implementation cost is expensive, it is valuable to adopt RFID solutions in container terminals in regard to the following perspectives:

- Internal tractor turning time. The return on investment of the vehicle tracking system can be reflected by a number of quantitative measures. First of all, it is possible to calculate the return on investment by the internal tractor turning time. In this study, the average turn time, including loading and discharging of containers by an internal tractor, is 18.5 minutes. After the implementation of the system, the turn time decreased to 15 minutes with reduction in traffic congestion. This reduction in means the Internal Tractor usage decreased. Thus, the operation cost is reduced significantly

- Labor cost. Another method to represent the return on investment is by measuring the labor cost. It is determined by the reduction in number of workers (to be hired). As the cycling time for assigning drivers is saved, the labor level is reduced. On the other hand, as the problems of traffic congestion are reduced, the number of drivers needed is also reduced. Furthermore, if the total time of tackling incidents decreases, the labor cost will also decrease. In this study, the time to handling an incident is decreased by $20 \%$ and the labor cost is reduced by $30 \%-40 \%$

\section{Conclusion}

In this study, the feasibility of using RFID in the container terminal is discussed. RFID equipment that is suitable to the container area is chosen, and the effectiveness of the vehicle tracking under different conditions is tested. The result of the tests is employed in the design. It is found that an RFID-enabled vehicle tracking system can be implemented in a container terminal in order to facilitate the container operation by monitoring traffic and assigning jobs to patrol car drivers. These could help the operators to work more efficiently and effectively in the following aspects: 
- Better Operation Management. By using the vehicle tracking system, the Control Tower can obtain information on every tractor which they could not get before the use of system. The location of the vehicle is tracked while the traffic condition is visible from the Control Tower. By using the information from the system, the Control Tower can have a better operation management. Also, the efficiency of the work in the Control Tower is increased

- Reducing time required to respond to emergencies. As the landside situation is visible to the Control Tower and they can obtain all real time information of the terminal, the staff in the Control Tower can react to incidents more quickly. On the other hand, they save time in finding vehicles which not being used for a long period. The tracking system helps the Control Tower to reduce the lead time in operation

- Assignment of job to a tractor that is situated nearest to the location. Although the system contains functions which assign jobs automatically, the tracking system helps the operation management system to assign jobs more efficiently. The Control Tower can make use of the vehicle tracking system to track the most recent location of a tractor and assign jobs to the nearest tractor so the work of transporting containers can be more efficient

- Provide Statistics for future operation. Apart from the operational benefit, the vehicle tracking system also provides the Operations Department of the container terminal with statistics. By using the statistics, such as average operation time or frequency of traffic congestion, drawn from the system, the Operations Department can have better future development. For example, the Operations Department can make use of the statistics in traffic congestion in order to construct better Yard Planning

- Driver behavior is tracked. Driver behavior can be checked by using the vehicle tracking system. As the data of the vehicle and its operation is being recorded, the Operations Department can use the data to analyze the performance of the drivers. For example, the frequency of a driver experiencing long waiting period can act as a performance assessment criteria

- Provide solution for routing. There is no system to track on how vehicles run in the terminal. By using the tracking system, the route of a vehicle can be tracked and recorded. By using this information, the Operations Department 
can analyze the usual driver's route and suggest better routing for driver to follow in order to reduce traffic congestion

From the above analysis, it is found that the vehicle tracking system not only facilitates the operation of the terminal, but statistics from the system helps in other areas. So, the system is worth to implement in the container terminal. However, before deciding whether to implement a tracking system in the terminal, more experiments on different RFID equipment is necessary in order to sort out the best.

\section{Acknowledgement}

The authors gratefully thank the Department of Industrial and Systems Engineering, The Hong Kong Polytechnic University for its support of this research work (project code: GYJ12).

\section{References}

Abad, E., Palacio, F., Nuin, M., Gonzalea de Zarate, A., Juarros, A., Gomez, J.M. et al. (2009). RFID smart tag for traceability and cold chain monitoring of foods: Demonstration in an intercontinental fresh fish logistic chain. Journal of Food Engineering, 93(4), 394-399. http://dx.doi.org/10.1016/j.jfoodeng.2009.02.004

Ayers, P.D., Wu, C., \& Anderson, A.B. (2004). Evaluation of autonomous and differential GPS for multi-pass vehicle tracking identification. ASAE paper no. 041061. St. Joseph, MI: ASAE.

Borriello, G. (2005). RFID: tagging the world. Communications of the ACM, 48(9), 34-37. http://dx.doi.org/10.1145/1081992.1082017

Cao, X.H. \& Xiao, H.B. (2011). Propagation prediction model and performance analysis of RFID system under metallic container production circumstance. Microelectronics Journal, 42(2), 247-252. http://dx.doi.org/10.1016/j.mejo.2010.12.004

Chao, S.L. \& Lin, P.S. (2009). Critical factors affecting the adoption of container security service: The shippers' perspective. International Journal of Production Economics, 122(1), 67-77. http://dx.doi.org/10.1016/j.ijpe.2008.12.021

Finkenzeller, K. (2003). RFID Handbook - Fundamentals and Applications in Contactless Smart Cards and Identification. Wiley. 
Haugen, L., Ayers, P., Anderson, A.B. \& Nissen, P. (2002). Using GPS to evaluate vehicle movement patterns and impacts during training maneuvers. Proceedings of the Vehicle and terrain mechanics in the 21st century virtual world, 14th International ISTVS Conference.

Hsieh, J.W., Yu, S.H., Chen, Y.S. \& Hu, W.F. (2006). Automatic traffic surveillance system for vehicle tracking and classification. IEEE Transactions on Intelligent Transportation Systems, 7(2), 175-187. http://dx.doi.org/10.1109/TITS.2006.874722

Hsu, C.I., Shih, H.H. \& Wang, W.C. (2009). Applying RFID to reduce delay in import cargo customs clearance process. Computers \& Industrial Engineering, 57(2), 506-519. http://dx.doi.org/10.1016/j.cie.2008.02.003

Jedermann, R., Behrens, C., Westphal, D. \& Lang, W. (2006). Applying autonomous sensor systems in logistics-Combining sensor networks, RFIDs and software agents. Sensors and Actuators, A 132, 370-375. http://dx.doi.org/10.1016/j.sna.2006.02.008

Kane, L., Vermaa, B. \& Jaina, S. (2008). Vehicle tracking in public transport domain and associated spatio-temporal query processing. Computer Communications, 31(12), 2862-2869. http://dx.doi.org/10.1016/j.comcom.2007.12.020

Kwok, S.K., Ting, J.S.L., Tsang, A.H.C., Lee, W.B. \& Cheung, B.C.F. (2010). Design and development of a mobile EPC-RFID-based self-validation system (MESS) for product authentication. Computers in Industry, 61(7), 624-635. http://dx.doi.org/10.1016/j.compind.2010.02.001

Kwok, S.K., Tsang, H.C., \& Cheung, B.C.F. (2008). Realizing the potential of RFID in counterfeit prevention, physical asset management, and business applications: case studies of early adopters. Department of Industrial and Systems Engineering, The Hong Kong Polytechnic University.

Lee, K., Oh, S.K. \& Ryu, H.Y. (2003). Application of high resolution satellite imagery to transportation: Accessibility index extraction approach. Proceedings of IEEE International Geosciences and Remote Sensing Symposium, 4, 2942-2944.

Ngai, E.W.T., Li, C.L., Cheng, T.C.E., Lun, Y.H.V., Lai, K.H., Cao, J. et al. (2010). Design and development of an intelligent context-aware decision support system for real-time monitoring of container terminal operations. International Journal of Production Research, 49(12), 3501-3526. http://dx.doi.org/10.1080/00207541003801291 
Park, J.S., Oh, S., Cheong, T. \& Lee, Y. (2006). Freight container yard management system with electronic seal technology. Proceedings of IEEE International Conference on Industrial Informatics, 67-72. http://dx.doi.org/10.1109/INDIN.2006.275719

Park, N.K., Dragovic, B. \& Kim, J.Y. (2009). Dynamic equipment deployment at a container terminal: Transfer system based on real-time positioning. Strojniski Vestnik-Journal of Mechanical Engineering, 55(2), 83-94.

Rus, C., Bilcu, R.C., Egiazarian, K., \& Rusu, C. (2004). Scanned maps processing using wavelet domain hidden Markov models. Proceedings of First International Symposium on Control, Communications and Signal Processing, IEEE, 451-454.

Wang, L.X., Kwok, S.K., Ip, W.H. \& Ng, P.H. (2009). Transportation visualization of perishable products with a RFID and Sensor network. IJIAP International Journal of Information Analysis and Processing, 2(2), 35-42.

Woo, S.H. Choi, J.Y. Kwak, C.J. \& Kim, C.O. (2009). An active product state tracking architecture in logistics sensor networks. Computers in Industry, 60(3), 149-160. http://dx.doi.org/10.1016/j.compind.2008.12.001

Journal of Industrial Engineering and Management, 2012 (www.jiem.org)

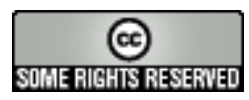

\footnotetext{
Article's contents are provided on a Attribution-Non Commercial 3.0 Creative commons license. Readers are allowed to copy, distribute and communicate article's contents, provided the author's and Journal of Industrial Engineering and Management's names are included. It must not be used for commercial purposes. To see the complete license contents, please visit http://creativecommons.org/licenses/by-nc/3.0/.
} 